\title{
Uma Times Square para Roma. Construções da cidade de Roma em produções midiáticas
}

A Times Square to Rome. Constructions of Rome in media productions

\author{
Una Times Square para Roma. Construcciones de la ciudad de Roma en las \\ producciones mediáticas
}

Victor Henrique da Silva Menezes ${ }^{1}$

Resumo: O presente trabalho tem como objetivo tecer algumas considerações acerca da forma como a cidade de Roma do século I. a.C foi representada no seriado Roma (20052007), produzido pelas redes de televisão HBO, BBC e RAI. Para tal, serão destacados alguns cenários e imagens apresentados na série, inspirados em centros urbanos modernos, bem como depoimentos de produtores, diretores e consultores de história que atuaram em sua produção. Por fim, serão ressaltadas algumas das possíveis influências do presente nos discursos que foram/são emitidos pela série por meio da cultura material apresentada.

Palavras-chave: Cinema; Cultura Visual; Roma Antiga; Representações; Cidades.

\begin{abstract}
This paper aims to make a few considerations on how the first century BC city of Rome was represented in the series Rome (2005-2007), produced by the television corporations $\mathrm{HBO}, \mathrm{BBC}$ and RAI. We will highlight some settings and images featured in the series, inspired by modern urban centers, as well as the testimonials from producers, directors and History consultants who worked for the series' production. Finally, some of the possible influences of the present in the discourses that were / have been generated by the series through its material culture will be analyzed.
\end{abstract}

Keywords: Cinema; Visual Culture, Ancient Rome; Representations; Cities.

Resumen: Este artículo tiene como objetivo hacer algunas observaciones acerca de cómo la ciudad de Roma del siglo I A.C fue representada en la serie Roma (2005-2007), producida por la cadena de televisión HBO, BBC y la RAI. Para esto, seran destacados algunos de los escenarios y las imágenes que aparecen en la serie, inspirada en los centros urbanos modernos, así como los testimonios de los productores, directores y consultores de la historia que actuaron en su producción. Por último, se puso de relieve algunas de las posibles influencias del presente en los discursos que fueron / son emitidos por la serie a través de la cultura material presentada.

Palabras clave: Cine; Cultura Visual; Roma Antigüa; Representaciones; Ciudades.

\section{Introdução} 1 Mestrando em História Cultural pela Universidade Estadual de Campinas (UNICAMP). Bolsista da Fundação de Amparo à
Pesquisa do Estado de São Paulo (FAPESP). Contato: $\underline{\text { henrique.menezes92@gmail.com }}$ 
A relação entre Cinema e Antiguidade Clássica $^{2}$ é quase tão antiga quanto a sétima arte (ANTELA-BERNÁRDEZ \& MARTÍN, 2013: 11; SKWARA, 2014: 164). Foram os franceses os responsáveis pela produção da primeira película ambientada no Mundo Antigo: o filme Neron essayant des poisons sur des esclaves, produzido pelos irmãos Lumière, dirigido por Georges Hatot e lançado em $1896^{3}$. Os italianos, por sua vez, afim de levar para as telas a história dos antigos romanos, tido como seus antepassados, foram os primeiros a utilizarem-se de descobertas arqueológicas na construção de cenários cinematográficos. Cabiria, filme mudo dirigido por Giovanni Pastrone e lançado em 1914, utilizou-se, por exemplo, da documentação arqueológica como inspiração para a construção de cenários da Roma Antiga. Esse mesmo filme, no entanto, para representar os cartagineses, inspirou-se nas pinturas neoclássicas do século XIX (ALONSO, 2013: 88). O aumento no interesse de levar a cultura material dos antigos romanos para as telas deu-se, contudo, com a ascensão do regime fascista na Itália em 1922. Nesse período Mussolini passou a financiar produções cinematográficas cuja as

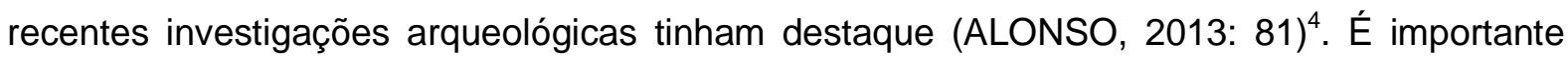
ressaltar que os descobrimentos arqueológicos utilizados nos filmes e documentários italianos da época tinham como objetivo primeiro a exaltação de uma hipotética grandeza romana. Grandeza essa que supostamente estaria presente nos italianos do século XX. A cultura material da Antiguidade era então levada às telas como meio de comprovar o elo que se acreditava existir entre os antigos romanos e os atuais italianos.

Após os acontecimentos da Segunda Guerra Mundial e o fim do regime fascista os cineastas italianos optaram por elaborar novas representações da sociedade romana antiga. Segundo o historiador espanhol Rafael de España (2013: 50) os filmes produzidos nos anos seguintes à deposição de Mussolini podem ser classificados como "filmes de reconciliação", uma vez que procuravam negar às ideias fascistas por meio da exaltação do catolicismo, tido nesse momento como uma ideologia do perdão e da tolerância, contrária aos abusos perpetuados pelo fascismo. Nesse período, ao invés de levar para as telas filmes que retratassem a expansão imperialista romana - como fora o caso de Scipione l'Africano (Dir. Carmine Gallone, 1937) -, optou-se por filmar enredos no qual o cristianismo tinha papel central, como Fabiola (Dir. Alessandro Blasetti, 1949) e Os últimos dias de Pompeia (Dir. Paolo Moffa, 1950). Nas duas décadas seguintes a Antiguidade Clássica passou a ser mostrada em produções de

${ }^{2}$ O termo Antiguidade Clássica é utilizado neste trabalho para designar a cultura greco-romana nas suas mais variadas manifestações (FUNARI, 2003: 31). Cabe destacar que não se entende a sociedade greco-romana como superior às demais sociedades da Antiguidade.

${ }^{3} \mathrm{O}$ filme dirigido por Hatot foi lançado apenas um ano após a primeira exibição de uma película pelos irmãos Lumière.

${ }^{4}$ Entre os principais filmes e documentários italianos produzidos no período fascista (1922-1943), cuja descobertas arqueológicas da Roma Antiga tinham papel preponderante, destacam-se: Il retorno di Roma (1926), Tripoli. I nouvi scavi di Leptis Magna (1934), II Duce in Libia (1937), Viaggi di S. M. il Re Imperatori in Libia (1938) e Segni di Roma in Africa. I recenti scavi di quella que fuo la romana Cirene in terra d'Africa (1940).

(C) Rev. Arqueologia Pública

\begin{tabular}{l|l|} 
Campinas, SP & v.9
\end{tabular} No.(11)

p.179-194 suplemento ISSN 2237-8294 
baixo custo, de cunho fantástico e que tinham como foco a figura de heróis como Hércules, Ursus e Maciste (ANTELA-BERNÁRDEZ, 2013: 156). Denominados de peplum ${ }^{5}$, estes filmes utilizaram Grécia e de Roma como pressuposto para a apresentação de heróis musculosos que chegavam às cidades antigas para salvar os oprimidos e libertá-los das garras de tiranos e governantes sem escrúpulos. A produção cinematográfica norte-americana, por sua vez, neste mesmo período passou por um boom de películas ambientas na Antiguidade Clássica, em especial na Roma Antiga 6 . Ao contrário dos peplum italianos, os épicos produzidos por Hollywood prezaram por retratar, em particular, a vida dos imperadores, dos cristãos e dos escravos, e exibiram construções monumentais da cidade de Roma. Arquétipos máximos dessas produções são as películas Quo Vadis (Dir. Marvyn Leroy, 1951), Ben Hur (Dir. William Wyler, 1959), Spartacus (Dir. Stanley Kubrick, 1960), Cleópatra (Dir. Joseph Mankiewicz, 1963) e A Queda do Império Romano (Dir. Anthony Mann, 1964).

Todas essas produções, italianas e norte-americanas, assim como as demais obras midiáticas, ao buscarem falar de momentos do Mundo Antigo, disseram muito mais sobre os ideais políticos, religiosos e de gênero de seu período de execução. Apoiados na iconografia neoclássica do século XVIII e XIX tiveram ainda, um papel fundamental no estabelecimento de uma ideia de Roma monumental, caracterizada por edifícios de grandes proporções e pela cor branca (MARCHENA, 2007: 04), numa alusão à ideia de uma cidade feita de mármore. Diante disso, o presente trabalho apresentará brevemente as características cenográficas da cidade de Roma nos filmes produzidos em especial por Hollywood entre os anos 1950 e 1960, para então tecer algumas considerações acerca da forma como a mesma cidade foi representada no seriado Roma (Dir. Druno Heller, John Millius e David MacDonald, 2005-2007), produzido pelas redes de televisão $\mathrm{HBO}, \mathrm{BBC}$ e RAI.

\section{De mármore branco: a cidade de Roma no cinema hollywoodiano das décadas de $1950 / 60$}

A cidade de Roma, desde os filmes mudos italianos da década de 1910 até os épicos hollywoodianos das décadas de 1950 e 1960, teve papel fundamental no desenvolvimento dos

\footnotetext{
${ }^{5}$ Atualmente, como escreve o historiador espanhol Borja Antela-Bernárdez (2013: 157), são denominados de peplum todos os filmes que procuraram/procuram representar momentos e personagens da Antiguidade, seja da civilização greco-romana ou, egípcia, mesopotâmica, celta, gaulesa, entre outras.

${ }^{6}$ É importante destacar que na primeira metade do século XX as películas com enredos ambientados na Antiguidade também estiveram presentes na indústria cinematográfica norte-americana. As películas italianas eram, nesse momento, as principais referências para a nascente Hollywood, que, ao término da Primeira Guerra Mundial, passou a marcar presença de forma significativa no cenário internacional. Destacaram-se nesse período os trabalhos dos cineastas D. W. Griffith - Judith de Betúlia (1913) e Intolerância (1916) -, e de Cecil B. De Mille, com os aclamados Os dez mandamentos (1912), O Rei dos reis (1927) e Cleópatra (1934).
} 
enredos ambientados tanto em histórias que buscavam representar episódios do período republicado de Roma, quanto do principado. Para além de desempenhar a função de criação de um contexto espacial, as representações da cidade serviram como meio de reforçar determinados juízos de valores acerca da sociedade antiga (MARCHENA, 2008: 232). Para a construção de ruas e prédios da Antiga Roma, o cinema utilizou-se menos das pesquisas arqueológicas que das pinturas neoclássicas dos séculos XVIII e XIX. O uso dessas pinturas na elaboração dos cenários referentes aos cartagineses no filme Cabiria em oposição aos 'cenários romanos', que para esse filme foram baseados grande parte em escavações arqueológicas, não foi a exceção. O mesmo procedimento foi seguido por outros cineastas italianos e norte-americanos para a construção da Antiguidade nas telas, e em particular da Roma Antiga. Os espaços urbanos, tanto interiores como exteriores, representados nas pinturas foram levados às telas sem grandes transformações e contribuíram na criação de determinadas percepções acerca das sociedades greco-romanas (MARCHENA, 2008: 234).

Uma das características das pinturas neoclássicas foi a concepção decadentista das sociedades da Antiguidade Clássica e a monumentalidade de suas cidades. Essa ideia é perceptível, por exemplo, na pintura Os romanos da decadência (1847), de Thomas Couture (Imagem 01). Nessa obra de Couture os romanos, ao centro da pintura, são mostrados como bêbados luxuriosos que participam de um bacanal. Na esquerda há um menino melancólico sentado em cima de uma coluna e à direita, dois visitantes estrangeiros que parecem desaprovar a cena. Ao redor desses personagens há um conjunto de estátuas antigas e, ao fundo, construções monumentais que representam, por certo, edifícios públicos. Todas as estátuas, assim como os prédios, possuem tons de branco. Essa ideia de Roma como uma cidade de edifícios monumentais e arquitetura branca estará presente em quase todos os filmes norte-americanos das décadas de 1950/60. Assim como todas as supostas estátuas antigas, compartilhando do ideal renascentista e neoclássico de beleza, serão mostradas como brancas. Tais características podem ser facilmente observadas em particular, mas não somente, no filme Cleópatra de Mankiewicz (Imagem 02).

O recente trabalho do arqueólogo alemão Vinzenz Brinkmann e de sua equipe (do Museu Glyptothek, em Munique) demonstrou, por meio de uma extensa pesquisa sobre a policromia antiga, que as estátuas da Antiguidade Clássica eram coloridas, e não brancas. 0 que induz a acreditar-se que os antigos gregos e romanos tinham predileção pelo colorido, ao

(C) Rev. Arqueologia Pública \begin{tabular}{l|l} 
Campinas, SP & v.9
\end{tabular} \begin{tabular}{|l|l|l} 
No.(11) & p.179-194 & suplemento
\end{tabular} ISSN 2237-8294 
invés do branco ${ }^{7}$, típico das estátuas e esculturas renascentistas e neoclássicas. Segundo Brinkmann, não eram apenas as estátuas que eram coloridas, mas também os templos, especialmente nas áreas superiores. Em entrevista para o site Terra no ano de 2013, o estudioso alemão explicou que os arqueólogos há muito tempo já tinham o conhecimento das cores presentes nas estátuas e que, "no final do século XIX, já não havia mais dúvidas entre os estudiosos: as esculturas de mármore gregas e romanas foram ricas em cores" ${ }^{\prime 8}$. Essa questão, no entanto, foi negligenciada em geral pelos estudiosos da Antiguidade no século $\mathrm{XX}$, e em particular pela indústria cinematográfica, que, ao buscar nas artes neoclássicas as suas inspirações, compartilharam de seu ideal do branco. Os cineastas, ao optarem por levar às grandes telas uma Roma próxima daquela construída nas pinturas do século XVIII e XIX seja por falta de informação das pesquisas arqueológicas, seja por decidirem seguir a tradição do ideal de branco -, elaboraram representações específicas da cidade. No quesito beleza, por exemplo, a cidade de Roma que aparece em seus filmes diz muito mais de um ideal moderno de perfeição, que daquele compartilhado entre os antigos.

Ainda, caracterizada como uma cidade imponente, Roma foi também construída nas décadas de 1950/60 como o palco da maldade e corrupção. Características essas que foram levadas às telas como sinônimo da cultura não-cristã predominante na cidade no século I a.C. e nas primeiras décadas da Era Comum. De acordo com as narrativas criadas por esses filmes, a corrupção nos costumes seria o fator preponderante para que os romanos fossem apaixonados pelas lutas de gladiadores e pelos martírios, que se tornaram marca das histórias ambientadas na Roma Antiga levadas às grandes telas ${ }^{9}$ (MARCHENA, 2008: 238). Tidos como característicos da cidade de Roma, tais espetáculos foram mostrados no cinema a semelhança de suas representações em pinturas como Pollice Verso (1872), de Jean Leon Gerone (Imagem 03), e Tochas de Nero (1877) de Henryk Siemiradzki (Imagem 04), por exemplo. Como escreve o historiador espanhol Óscar Lapeña Marchena, nessas produções:

(...) Las carreras de cuádrigas, las ocasionales naumaquias, los combates de gladiadores y las ejecuciones de cristianos se muestram como

\footnotetext{
${ }^{7}$ Os resultados dessa pesquisa possibilitaram a organização da exposição Gods in Color: Painted Sculpture of Classical Antiquity que, desde 2004, foi exibida em países como Alemanha, Inglaterra e Estados Unidos.

8 "Arqueólogo: século 20 negligenciou as cores das estátuas gregas". Reportagem de Matheus Pessel para o site http://noticias.terra.com.br/. Acessado em 29/06/2015.

${ }^{9}$ Algumas das produções cinematográficas sobre os antigos romanos, além de inspirarem-se nas artes neoclássicas, foram baseadas em romances históricos escritos no século XIX e primeira metade do XX. Exemplos de obras literárias adaptadas para o cinema nas décadas de 1950 e 1960 são: Os últimos dias de Pompeia (1834), de Edward George Bulwer-Lytton; Fabíola (1854), de Nicholas Wiseman; Ben Hur (1880), de Lew Wallace; Quo Vadis? (1895), de Henryk Sienkiewicz; e Spartacus (1951), de Howard Fast.
} 
espectáculos habituales, casi cotidianos, que se desarrolan bajo la atenta mirada y passional complicidad de uma audiência que colma los graderíos. [...] Carros, leonês, gladiadores y cristianos parecen ser los únicos habitantes - junto al pueblo ocioso que los observa - de la civilización romana. (MARCHENA, 2008: 236)

Após a década de 1970, a indústria cinematográfica norte-americana privilegiou outros temas e períodos históricos em suas produções, e a cidade de Roma, bem como a Antiguidade, ficou distante das grandes telas estadunidenses ${ }^{10}$. Passaram-se mais de trinta anos até que, às vésperas do século XXI, o diretor Ridley Scott desenterrou o gênero épico de filmes ambientados na Antiguidade com a película Gladiador (2000). Sucesso de bilheteria, o filme de Scott precedeu uma série de outras produções cujo Mundo Antigo no geral, e a cidade de Roma em particular, voltaram a ser o palco de seus enredos. Desde então, pode-se inferir que houve uma retomada pela mídia cinematográfica e o surgimento de produções televisivas norte-americanas que, guardadas as suas particularidades, representam momentos e personagens da Antiguidade no estilo épico das décadas de 1950/60. O ápice dessas produções, por certo, foi o seriado Roma (2005-7), cuja construção da cidade que dá o nome à série é ímpar.

\section{Uma moderna metrópole: a Roma de Heller, Milius e MacDonald}

O seriado Roma foi criado por Bruno Heller, John Milius e William J. MacDonald, produzido pelas redes de televisão HBO (Estados Unidos) e BBC (Inglaterra), em parceria com a RAI (Itália) e teve como consultor de História o mestre em Estudos Clássicos por Oxford e documentarista da BBC Jonathan Stamp ${ }^{11}$. A série começa em 52 a.C, quando Júlio César derrota Vercingetórix na batalha de Alésia, e termina em 27 a.C, com a morte de Marco Antônio e Cleópatra, e a ascensão de Otávio Augusto como o primeiro imperador romano. Para ambientar a transição da antiga Roma republicana para a Roma imperial a série retrata não apenas a elite romana, mas também as chamadas classes baixas. Além de Júlio César,

\footnotetext{
${ }^{10}$ Apesar de não haver o que a crítica denominou de épicos hollywoodianos ambientados no Mundo Antigo sendo produzidos entre as décadas de 1970 e 1990, a Antiguidade Clássica não desapareceu do cinema. De narrativas e representações diversas daquelas características do cinema estadunidense e italiano das décadas de 1950 e 1960 foram produzidas obras como: $A$ Funny Thing Happened on the Way to the Forum (Dir. Richard Lester, Inglaterra, 1966), Édipo Rei (Dir. Pasolini, Itália, 1967), Medeia (Dir. Pasolini, Itália, 1969), Satyricon (Dir. Frederico Felini, Itália, 1969), As Troianas (Dir. Michael Cacoyanis, EUA, 1971), A Vida de Bryan (Dir. Terry Jones, Inglaterra, 1979), Calígula (Dir. Tinto Brass, Itália/EUA, 1979) e Hércules (Dir. Ron Clements, EUA, 1997). A representação da cidade de Roma, quando essa aparecia, foi diversa: enquanto algumas películas continuaram a inspirar-se nas artes neoclássicas, houve algumas rodadas em cenários naturais, ou, nas atuais ruinas da cidade antiga, que deixaram de lado a ideia de reconstruções monumentais dos edifícios (MARCHENA, 2008: 251).

${ }^{11}$ A série, composta por 22 episódios (12 em sua primeira temporada e 10 na segunda), foi filmada nos estúdios Cinecittà, na Itália. Atualmente é considerada como uma das séries de televisão mais premiada e cara da história, com o custo de UU $\$ 100$ milhões por temporada. Foi transmitida originalmente entre 28 de agosto de 2005 e 25 de março de 2007.
} 
Pompeu, Marco Antônio, Cleópatra e Otávio Augusto, figuras históricas já amplamente conhecidas do público, ganham destaque também personagens como o centurião Lúcio Voreno e o legionário Tito Pullo (mencionados por César no livro $\mathrm{V}$ de sua obra De bello gálico) e inúmeras personagens fictícias, como Níobe, esposa de Voreno. Como destacado pela historiadora norte-americana Monica S. Cyrino (2008: 06), Roma é diferente de qualquer outra representação do Mundo Antigo, pois, ao contrário dos épicos das décadas de 1950/60, a série "ressalta visualmente a conexão entre as personagens da elite e aquelas das classes mais baixas sem lançar nenhum juízo de valor quanto à moral relativa de qualquer um". $\mathrm{Na}$ série a dualidade bem vs mal não é definida, como no filme Spartacus (1961) por exemplo, a partir das classes sociais representadas. E a igualdade na forma de pensar e agir é enfatizada de propósito, na ideia de que ricos e pobres, ao serem romanos, possuíram algumas características culturais em comum (CYRINO, 2008: 07).

A cidade de Roma, por sua vez, foi representada de forma suja, degradada e com animais soltos pelas ruas, o que remete a uma impressão de velhice. Segundo Daniel Acon, supervisor de efeitos especiais, isso foi colocado nas telas porque historicamente, Roma seria diferente da imagem que foi construída pelos pintores neoclassicistas, uma vez que era "suja, molhada e úmida por causa dos aquedutos, e havia muita ação entre incêndios, fumaça e canos vazando"12. Além disso, as construções no período em que se passa a série em sua maioria já possuía mais de duzentos anos, e, por isso, teriam formas envelhecidas. O produtor executivo e roteirista Bruno Heller, nas informações especiais contidas no DVD de Roma explicou que a proposta geral da série:

"Não era de impressionar pelo espetáculo e por efeitos visuais, porque é muito fácil deixar tudo maravilhoso, incrível, grandioso e não lidar realmente com os personagens. (...) A ideia original era criar a cidade como ela era, cheia de pedras, encardida, suja e esfumaçada, o contrário do clichê cinematográfico de Roma, com suas muralhas de mármore, tudo limpo e majestoso" ${ }^{\prime 13}$.

Percebe-se, por meio de suas falas, que o intuito dos produtores e roteiristas da série era de retratar Roma o mais perto possível da realidade ${ }^{14}$, não deixando, nas palavras de

\footnotetext{
${ }^{12}$ Transcrição do depoimento de Daniel Acon para os extras do DVD da primeira temporada de Roma disponível no Disco 06.

${ }^{13}$ Transcrição do depoimento de Bruno Heller para os extras do DVD da primeira temporada de Roma. Depoimento disponível no Disco 06.

${ }^{14}$ A historiadora norte-americana e professora de Estudos Clássicos do Barnard College de Nova York Kristina Milnor (2008: 4248) comentou, em artigo sobre Roma, a experiência dela como consultora histórica dos dois primeiros episódios da série. Um dos pontos mais destacados por ela foi o desejo constante, por parte dos produtores, de ser fiel aos acontecimentos do passado. Esse desejo e a crença na possibilidade de executá-lo era tão forte que segundo Milnor (2008: 44) um dos assistentes dos produtores executivos chegou a solicitar que ela traduzisse expressões em inglês para as línguas que os nativos da Gália falavam no século I
} 
Heller, que o seriado "soasse apenas como reprodução barata de sua época, parecendo fruto de colagens aleatórias de diversas épocas sob as quais se coloca uma camada de moralidade moderna"15. Tais afirmações, porém, permitem questionamentos acerca do quão ilusório é o pensamento dos produtores de Roma, uma vez que filmes e programas de TV, como assinalam Feitosa e Vicente (2012: 182) são construções idealizadas por um ou mais indivíduos não como espelho da sociedade, e muito menos reprodução da História do modo como aconteceu, mas sim como uma interpretação e construção dela. Portanto, é pouco provável encontrar na produção a realidade acerca da sociedade romana antiga, mas apenas aparências de realidade, que estão influenciadas por problemáticas do período histórico em que a série foi produzida. Exemplo interessante de influências do presente numa produção que diz ser de "fidelidade impressionante" é no que os produtores se basearam para montar a cidade de Roma. Bruno Heller, que em outro momento defendera produzir um trabalho que não soasse como produção cerca de costumes e moralidades modernas, ao tratar da forma como o diretor de arte Joseph Bennett trabalhou com a construção da Roma cenográfica explica que:

"Ao contrário de pessoas que vieram com pesquisas históricas, Joe veio com as coisas bizarras: fotografias de Mary Ellen Frank, imagens de Mumbai, da Cidade do México e dos interiores da velha Havana; era claro que ele tinha habilidades técnicas rigorosas, mas também uma estética nova e imaginativa sobre como deveria ser, e queríamos que ficasse autêntico e preciso, mas também estranho e belo, e Joe captou isso imediatamente"16.

Joseph Bennett, por sua vez, explica que escolheu ter essas cidades como modelo para a construção de Roma com o intuito de se afastar das tradicionais interpretações da cidade baseadas nas obras produzidas pelos pintores neoclássicos:

"Muitas das interpretações de Roma foram de pintores clássicos dos séculos XVII e XVIII. Neste caso estão interpretando uma versão meio romantizada de Roma. O que queríamos tentar fazer era algo mais honesto e fidedigno à vida. (...) algo vivo, pulsante, movimentado e que se tornasse uma personagem. (...) algo como a cidade de Nova York, que está sempre em movimento, com uma mistura de pessoas e carros indo e vindo a todo o momento, muito barulho, conversa, cansaço, fúria e certa pitada de diversão e esplendor. (...) como a Times Square ou o Piccadilly Circus, algo assim. Sempre havia coisas acontecendo. Coisas sendo tiradas, demolidas. Era um lugar orgânico" 17

a.C. Milnor, de forma burlesca, comenta que produtores da série estavam em busca de alguém que falasse Ubuan, uma suposta língua das tribos gaulesas, e que ficaram decepcionados com a explicação dela de que não havia sequer registros da existência dessa língua.

${ }^{15}$ Idem.

${ }^{16}$ Idem.

17 Transcrição do depoimento de Joseph Bennett para os extras do DVD disponível no Disco 06 da $1^{\underline{a}}$ Temp. 
Ao assistir o seriado é possível desprender-se da chamada "Roma Sagrada", característica das produções cinematográficas das décadas de 1950/60, e deparar-se com uma Roma parecida, em suas estruturas materiais, com as cidades indianas atuais e com a mesma movimentação da cidade de Nova York - há escravos, patrícios, plebeus e estrangeiros circulando pelas ruas da cidade em quase todos os momentos em que são mostradas. A Roma construída para a série possui a sua própria Times Square. Tais características são perceptíveis já no primeiro episódio da série em uma das primeiras tomadas em que aparece a cidade de Roma. Na cena, que ocorre por volta do décimo primeiro minuto do episódio é mostrada uma das principais vias da cidade onde há uma multidão de pessoas, carros e animais que cruzam a rua em meio a comerciantes e vendedores de frutas, de legumes e de flores. Há, de fato, muitas coisas acontecendo ali, como sugerira Bennett. Há uma movimentação semelhante ao que é possível observar nos dias atuais em lugares como a Times Square em Nova York e no Piccadilly Circus em Londres. Os prédios, que aparecem ao fundo da cena, são marcados por tons de cinza. Apesar de terem certos detalhes em vermelho, a sujeira e as marcas de incêndio são predominantes nesses edifícios. O mesmo pode-se observar das ruas e calçadas, que demonstram sinais de uma cidade envelhecida. A cor branca é praticamente inexistente (Imagem 05).

Se cidades como Nova York e Londres serviram de inspiração para a criação do centro de Roma, Habana e Mumbai, no entanto, parecem ter sido a base para a construção dos bairros afastados do centro, como Suburra (Imagem 06). A cidade apresentada na série, portanto, da mesma forma que aquela construída pelos épicos do século $\mathrm{XX}$, está distante do que teria sido a Roma do século I a.C. Essa nova interpretação da cidade de Roma Antiga é também subjetiva e tão criticável quanto as representações anteriores. Utilizar de cidades indianas e latino-americanas como exemplo para construir os subúrbios da cidade cenográfica, é afirmar - mesmo que involuntariamente - que alguns setores de Mumbai, por exemplo, estão num estágio de desenvolvimento que Roma passou há mais de dois mil anos. Enquanto que, sugerir que a parte central de Roma tivesse possuído características semelhantes aos de grandes centros políticos e econômicos atuais induz à ideia de descendência das atuais cidades de Londres e Nova York da antiga Roma. É a arcaica ideia,

\begin{tabular}{|l|l|l|l|l|l|l|}
\hline (C Rev. Arqueologia Pública & Campinas, SP & v.9 & No.(11) & p.179-194 & suplemento & ISSN 2237-8294 \\
\hline
\end{tabular} 
mostrada de uma nova maneira, de que o presente e o passado estão separados por uma linha reta, sem rupturas ou transformações. E que a 'civilização ocidental' é herdeira direta das sociedades greco-romanas.

A abertura da série também traz representações interessantes da cidade de Roma. Nela é perceptível ainda mais a ideia de que a Roma Antiga era semelhante à uma metrópole moderna, com inúmeros edifícios e ruas movimentadas. Destacam-se também a aparição de pinturas parietais e grafites, inspirados naqueles encontrados em escavações na cidade de Pompeia, ao longo da abertura. Tais pinturas, ao serem mostradas de forma animada, dão a ideia de que tudo está em constante movimento em Roma. O uso de materiais encontrados nas escavações de Pompeia, e mesmo em Roma, por sua vez, não se restringiu à abertura de Roma, uma vez que tais materialidades apareceram como alguns dos adereços das casas da elite e mesmo dos moradores de Suburra. A historiadora norte-americana Alena Allen (2008: 182), estudiosa das recepções do Mundo Antigo nas mídias visuais, comenta que o triclinium da domus da personagem Átia, mãe de Otávio Augusto, é semelhante ao encontrado em escavações numa antiga uilla romana, a Villa Farnesina. Ainda, tanto os esquemas de cores quanto os afrescos presentes nas paredes da casa de Átia lembram aqueles encontrados nas casas escavadas em Pompeia. As figuras femininas no átrio da domus de Servília, mãe de Brutus, são réplicas daquelas também encontradas na Villa Farnesina (ALLEN, 2008: 183). O apartamento de Voreno e Níobe, localizado em uma das insulae ${ }^{18}$ de Suburra, contém um pequeno afresco acima do santuário do deus Lar que é uma cópia de um afresco real encontrado em uma cozinha de Pompeia ${ }^{19}$ (ALLEN, 2008: 189).

Pode-se inferir que o uso da cultura material romana encontrada em escavações e o cuidado artístico ao reproduzir os afrescos é mais um indício do interesse dos criadores da série em serem 'fiéis' ao passado. Os produtores, portanto, esforçaram-se para simular a vida na Roma Antiga na época da morde de Júlio César sem parecer que estavam construindo simulacros (HAYNES, 2008: 50). Para ganhar os telespectadores, no entanto, não basta as telas construírem representações que parecem ser reais, mas, como apontado por Holly Haynes (2008: 50), a "representação do passado deve ser algo com o qual os telespectadores

\footnotetext{
${ }^{18} \mathrm{Na}$ cidade de Roma só os ricos conseguiam pagar até mesmo por uma modesta domus. A maioria das pessoas viviam em grandes blocos de apartamentos chamados insulae (ilhas), que muitas vezes, ocupavam um quarteirão inteiro. De três ou mais andares as insulae eram feitas de tijolo ou madeira. Em bairros mais pobres, a sua superlotação e os incêndios eram comuns.

${ }_{19}$ Apesar dos produtores não se inspirarem nas pinturas neoclássicas na construção exterior dos edifícios e ruas da cidade de Roma, é válido destacar que, nos interiores das domus de algumas personagens, tal influência também se faz notar. É o caso, por exemplo, de alguns cômodos da casa de Servília, onde há uma forte presença do mármore branco com toques de azul, muito
} semelhante aos cômodos da casa de Crasso em Spartacus de Kubrick (ALLEN, 2008: 185). 
possam se identificar". Ao mostrar as ruas de Roma a semelhança de uma metrópole moderna os produtores estavam talvez em busca de tal intento. Isso pode demonstrar que, mesmo que não seja o intuito de um roteirista ou diretor, a realização de uma ficção histórica se "justifica" de forma involuntária pela aproximação com o presente, e não pelo desejo de reconstruir fatos históricos (VIEGAS, 2001: 43). Com tais argumentos, não se procura tirar a credibilidade do seriado Roma como produto midiático, que possui um espetáculo visual belíssimo, roteiros inteligentes e atuações brilhantes (CYRINO, 2008: 03), mas, destacar o quanto e como conceitos e percepções modernas estão inseridas em produções cinematográficas e televisivas de época. Essas, assim como as produções historiográficas e arqueológicas, não ilustram nem reproduzem um suposto passado real, mas, como lembrado por Lourdes Feitosa e Maximiliano Vicente (2012: 181), o constroem a partir de uma linguagem própria produzida num determinado momento histórico.

\section{Considerações finais}

Na Antiguidade o imperador César Augusto (63 a.C - 14 d.C.) difundiu o discurso de que ele havia encontrado - no início de seu governo - uma cidade [Roma] de pedras e a havia transformado em uma cidade de mármore (Suetônio, Vida de Augusto, 28. 3). Os artistas do período que convencionou-se chamar de "Renascimento" relacionaram essa ideia de uso do mármore com a cor branca. Os pintores neoclássicos ao retratarem a cidade de Roma também optaram por mostrá-la branca, toda feita de mármore e monumental. O cinema hollywoodiano das décadas de 1950/60 em particular, ao dialogar com as artes plásticas também reproduziu essa imagem da cidade de Roma. Mesmo produções que buscaram retratar períodos anteriores aos de Augusto, como os das Guerras Púnicas, dos últimos anos da República, e também, períodos posteriores, retrataram a cidade com essas mesmas características. Aqui percebe-se que houve escolhas no tipo de Roma que se procurou representar. Essas escolhas não foram neutras e dizem muito da relação estabelecida entre o Mundo Contemporâneo e o Mundo Antigo.

Interessante notar que tal tradição na representação de Roma irá sofrer alterações apenas recentemente, no seriado Roma (2005-2007), conforme foi discutido neste trabalho. Nesta produção, a inspiração para a construção dos cenários foram outras, mas de nenhuma forma, menos subjetiva do que aquelas que optaram por mostrar Roma como uma cidade de 
mármore. Diante das representações visuais construídas pela série e dos discursos dos produtores discutidos compreende-se que Roma, assim como todas as produções midiáticas de cunho histórico, está influenciada por ideologias, gostos e políticas do tempo e das sociedades que a produziram. E que as suas representações, ao serem novas criações acerca do que teria sido a cidade de Roma, afetam a maneira como os telespectadores irão entender os antigos romanos. Não foi o intuito apontar as maneiras corretas de se representar a antiga cidade de Roma, uma vez que se acredita ser impossível tal intento. Mas sim, discutir de maneira breve os possíveis discursos construídos acerca da Antiguidade Clássica a partir da cultura material mostrada nas telas; demonstrando que tais discursos não são neutros e estão imbuídos de múltiplos significados.

\section{Imagens (Artigo de Victor Henrique S. Menezes)}

Imagem 01: Thomas Couture (1815-1879). Os romanos da decadência (1847). Óleo sobre

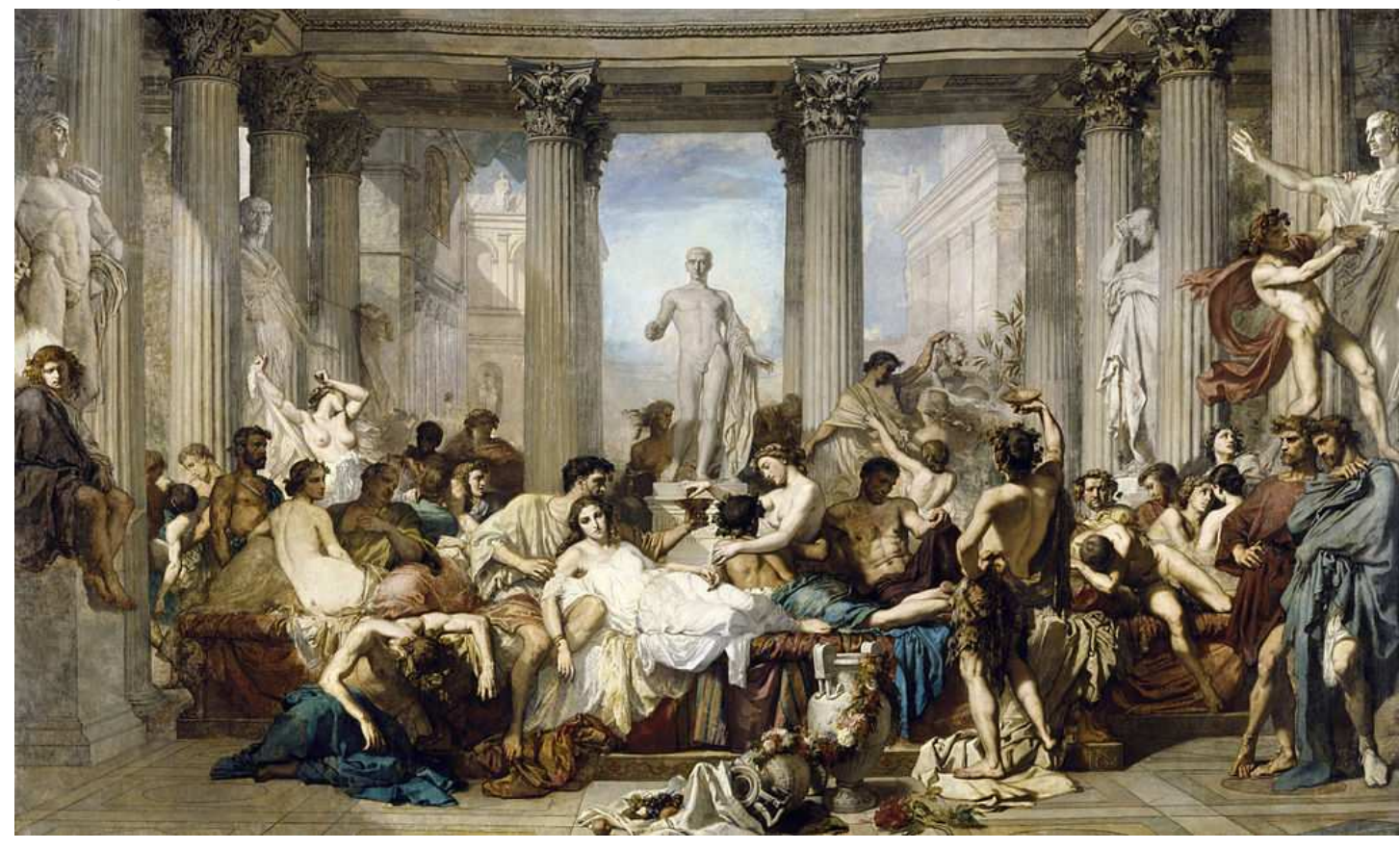

tela.

Alt.

472;

Anch.

772

cm (C)

RMN-

Gran

d

Palai

$\mathrm{S}$

(Mus

ée

d'Ors

ay) /

Herv

é

ndowski

Lewa

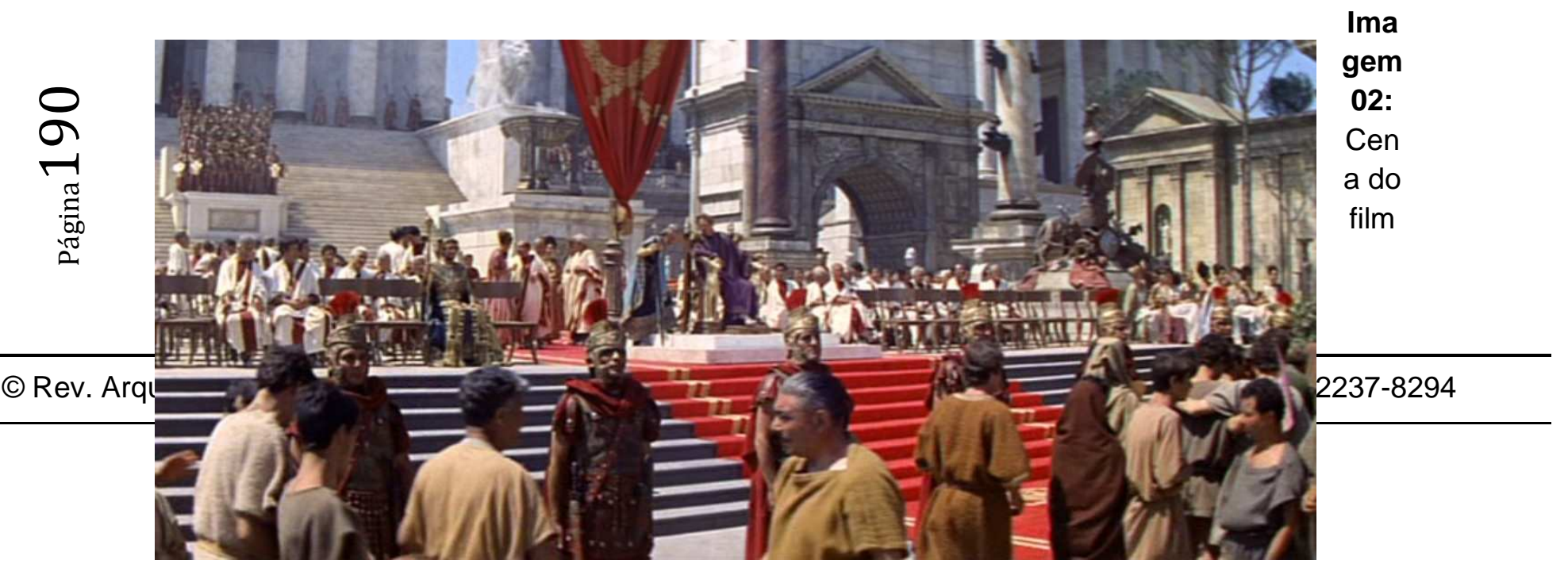


e

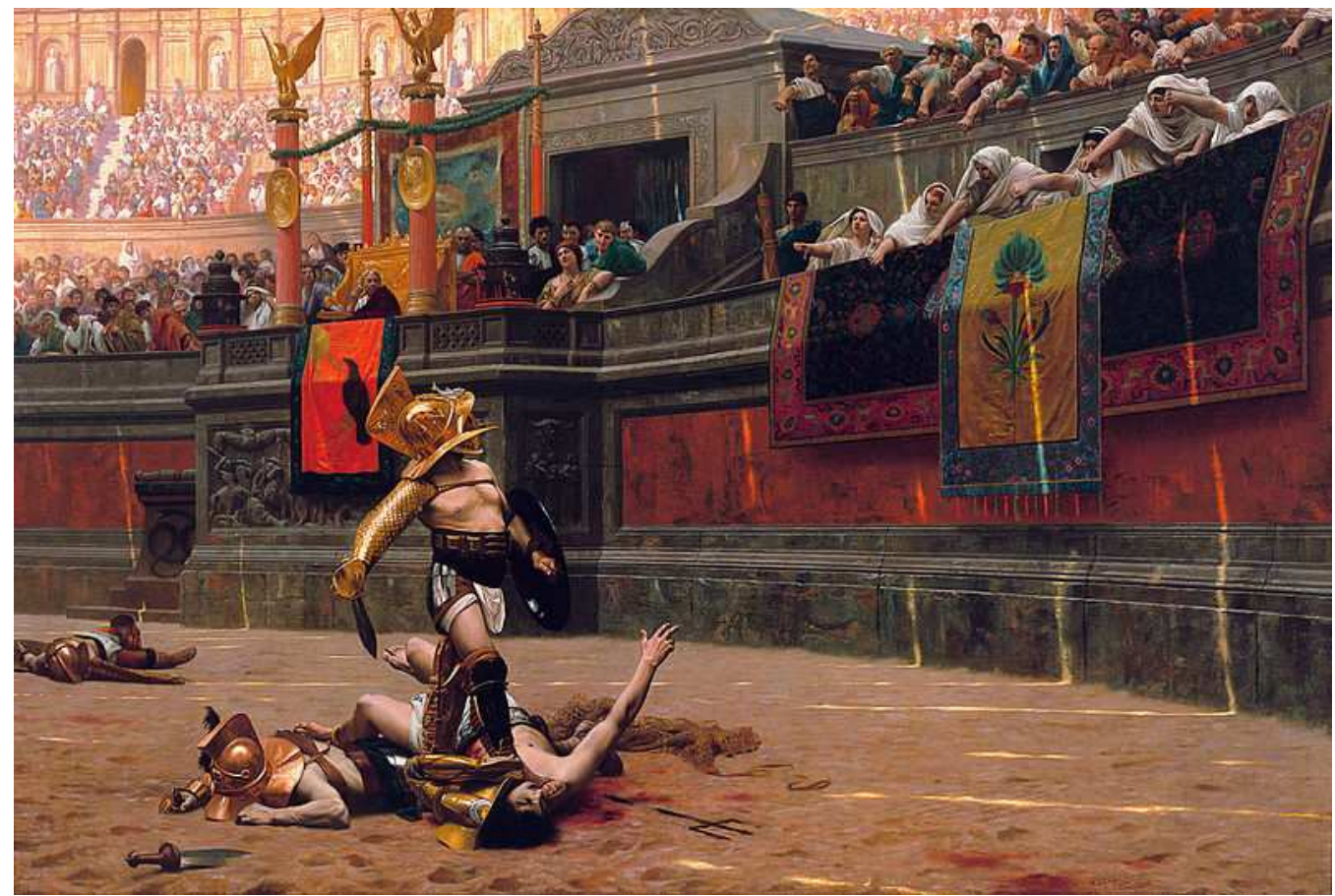

Cleópatra (Dir. Joseph Mankiewicz, 1963). Localização: DVD 01, 1h20min. Observações: No filme Cleópatra a cidade de Roma é representada de forma monumental e limpa. Nessa cena é possível observar os edifícios públicos e as estátuas de mármore, todos em tons de branco.

Imagem 03: Jean Leon Gerone (1824-1904). Pollice Verso (1872). Óleo sobre tela. Phoenix Art Museum, Arizona, Estados Unidos.

Imagem 04: Henryk Siemiradzki (1843-1902). Tochas de Nero (1877). National Museum,

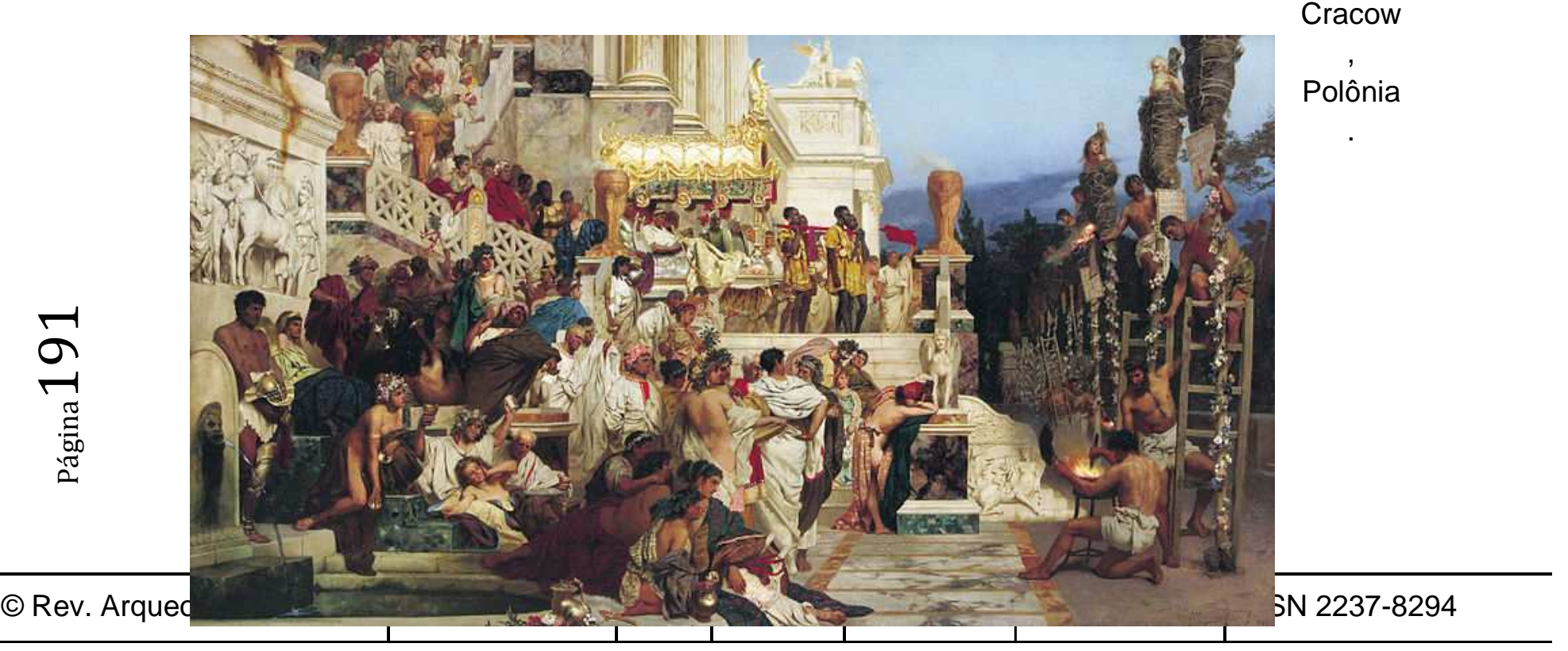




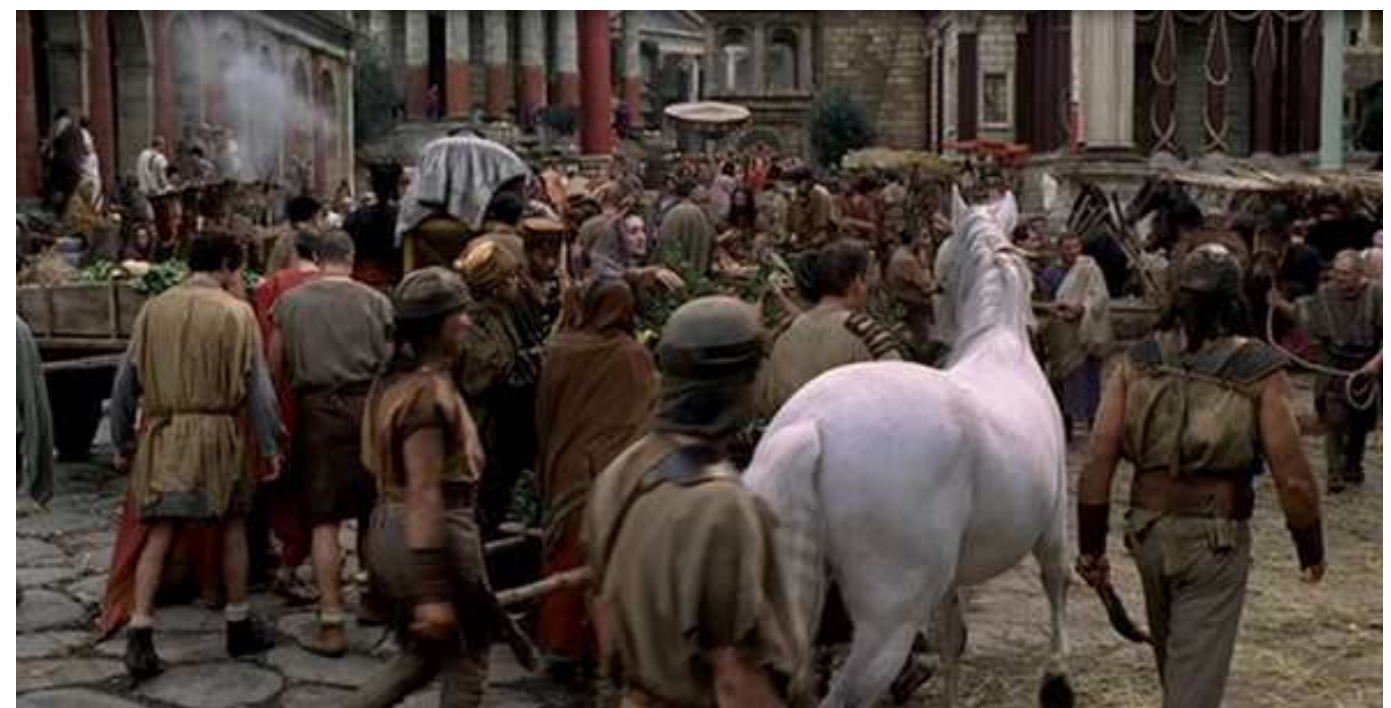

Imagem 05: Cena do seriado Roma (2005-2007). Localização: 1르 Temp, Disco 01, Episódio 01 ("A Águia Roubada), 11min. Observações: Nessa toma é mostrada uma das principais vias da cidade de Roma. Segundo os produtores da série a ideia era mostrar que $R$ oma foi uma capital 'viva', onde se tinham muito movimento, pessoas e animais por todo o lado. Uma ideia de que Roma seria tão 'fervilhante' quanto as principais capitais do mundo contemporâneo.

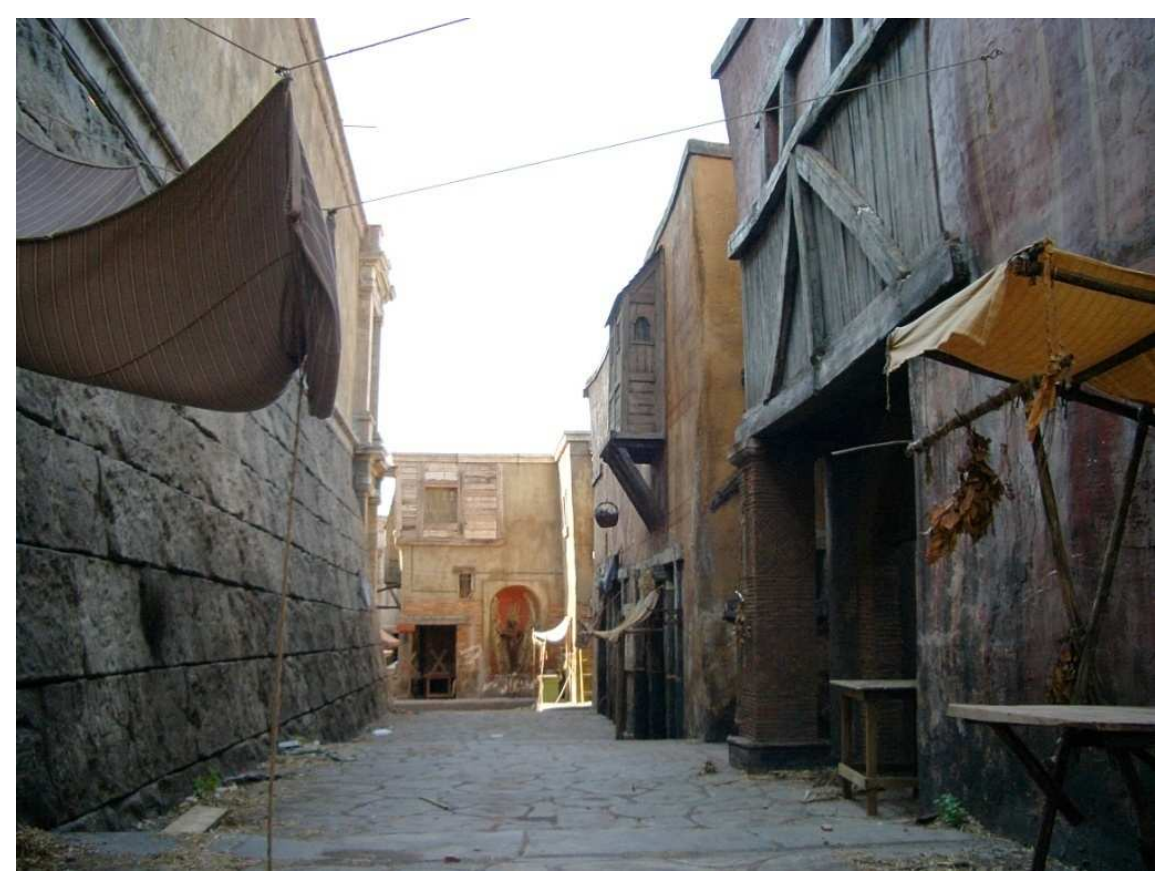

Imagem 06: Cena do seriado Roma (2005-2007). Localização: Disco 06, no extra "Em Roma". Observações: Imagem de um dos pontos da cidade cenográfica de Roma construída para a série Roma. Os produtores da série inspiraram-se em cidades como Habana e Mumbai para

\begin{tabular}{|l|l|l|l|l|l|l|}
\hline (C) Rev. Arqueologia Pública & Campinas, SP & v.9 & No.(11) & p.179-194 & suplemento & ISSN 2237-8294
\end{tabular}


construírem alguns elementos da Roma do seriado, em particular, no que concerne aos seus subúrbios, como Suburra.

\section{Referências bibliográficas}

\section{Obras da Antiguidade}

SUETÔNIO. "O divino Augusto". In. As vidas dos doze Césares. 5. ed. São Paulo, SP: Atena, 1956.

\section{Obras midiáticas}

HELLER, Bruno; MILIUS, John; MACDONALD, William J. Roma; BBC, HBO, RAI. 28 de agosto de 2005 a 25 de março de 2007.

\section{Obras modernas}

ALLEN, Alena. "Staging interiors in Rome's Villas". In CYRINO, Monica S. (Org.) Rome, season one: history makes television. Malden, MA: Blackwell Pub., 2008.

ALONSO, Francisco G. "Arqueología, cine y fascismo". In ANTELA-BERNÁRDEZ, B.; MARTíN, C. S. (Org.). La Historia Antigua a través del cine - Arqueología, Historia Antigua y Tradición Clássica. Barcelona: Editorial UOC, 2013.

ANTELA-BERNÁRDEZ, B. "Nouvelle péplum? Nuevas corrientes en el cine sobre la Antigüedad". In ANTELA-BERNÁRDEZ, B.; MARTíN, C. S. (Org.). La Historia Antigua a través del cine - Arqueología, Historia Antigua y Tradición Clássica. Barcelona: Editorial UOC, 2013, p. 155-164.

CYRINO, Monica S. (Org.) Rome, season one: history makes television. Malden, MA: Blackwell Pub., 2008.

ESPAÑA, Rafael. "La Antiguedad al servicio de la actualidad. Cómo las ideas del presente influyen en la recreación cinematográfica del passado". In ANTELA-BERNÁRDEZ, B.; MARTín, C. S. (Org.). La Historia Antigua a través del cine - Arqueología, Historia Antigua y Tradición Clássica. Barcelona: Editorial UOC, 2013.

FEITOSA, Lourdes M. G. C.; VICENTE, Maximiliano C. "Masculinidade do soldado romano: uma representação midiática". In CARVALHO, M. M.; FUNARI, P. P. A.; CARNAN, C. U.; SILVA, E. C. M. (Org.) História Militar do Mundo Antigo: Guerras e Representações. São Paulo: Annablume, 2012; p. 177-191

FUNARI, Pedro P. A. Antiguidade clássica: a história e a cultura a partir dos documentos. 2. Ed. Campinas, SP: Unicamp, 2003.

HAYNES, Holly. "Rome's Opening Titles: triumph, spectacle and desire". In CYRINO, Monica S. (Org.) Rome, season one: history makes television. Malden, MA: Blackwell Pub., 2008, p. 49-60.

MARCHENA, Óscar L. Hacia un passado común. El cine y la uniformización de la Antigüedad Clássica. Apuntes para su estudio. Methodos - Revista Electrónica de Didáctica del Latín, 2007, p. 1-15.

MARCHENA, Óscar L. La ciudad antigua en el cine: mucho más que un decorado. Congresso Internacional "Imagines". La Antiguedad en las Artes escênicas y visuales: Universidad de la Rioja, Logroño 22-24 de octubre de 2007. Coord. María Josefa Castillo Pascual, 2008, p. 231-252. 
SKWARA, Ewa. Quo Vadis on film $(1912,1925,1951,1985,2001)$. The many faces of Antiquity. CLASSICA. Revista brasileira de estudos clássicos, 2014, p. 163-174.

VIEGAS, Ana C. Gladiador: uma arena de imagens. Alceu, v. 01 - no 02 - p. 42 a 47 - jan/jun de 2001. 